Check for updates

Cite this: Phys. Chem. Chem. Phys., 2017, 19, 17199

Received 2nd May 2017,

Accepted 14th June 2017

DOI: $10.1039 / c 7 c p 02865 b$

rsc.li/pccp

\section{On the feasibility of reactions through the fullerene wall: a theoretical study of $\mathrm{NH}_{x} \mathrm{aC}_{60}{ }^{\dagger}$}

\author{
Pavlo O. Dral (D) *ab and Timothy Clark (D)*a
}

We propose a new approach to the synthesis of $\mathrm{AH}_{x}$ afullerene structures via reactions through the fullerene wall. To investigate the feasibility of the approach, the step-by-step hydrogenation of the template endofullerene $\mathrm{NaC}_{60}$ up to $\mathrm{NH}_{4} \mathrm{aC}_{60}$ has been studied using DFT and MP2 calculations. Protonation of the endohedral guest through the fullerene wall is competitive with escape of the guest, whereas reaction with a hydrogen atom is less favorable. Each protonation step is highly exothermic, so that less active acids can also protonate the guest with less accumulation of energy. The final product, $\mathrm{NH}_{4} \mathrm{OC}_{60}$ is a novel concentric ion pair $\mathrm{NH}_{4}{ }^{+} \mathrm{aC}_{60^{\circ}}{ }^{-}$in which the charge-centers of the two ions coincide.

\section{Introduction}

The inner wall of fullerenes is essentially chemically inert because of its concave shape. ${ }^{1}$ This inertness allows, for instance, a nitrogen atom in its quartet state to be encapsulated within $\mathrm{C}_{60}$ with a significant barrier to release and without it reacting with the fullerene. ${ }^{2-4}$ Before this species was reported, only the cations of electropositive metals ${ }^{5-7}$ or noble-gas atoms ${ }^{8-14}$ had been observed as endohedral guests within fullerenes. A series of species ranging from hydrogen ${ }^{15,16}$ and nitrogen ${ }^{17,18}$ molecules, water, ${ }^{19}$ carbon monoxide ${ }^{18}$ to transition metal atoms and ions (see, for example, reviews ${ }^{20,21}$ and references therein), carbides, ${ }^{20}$ nitrides, ${ }^{20}$ oxides $^{20}$ and intermetals ${ }^{22-24}$ have since been incorporated into fullerenes to give stable endofullerene derivatives.

Most of the above examples of the endofullerenes were synthesized by constructing or reclosing the fullerene cage in the presence of the moiety to be incorporated. Only the noble gases@ $\mathrm{C}_{60}$ were obtained by colliding accelerated charged, closed fullerene with atoms. ${ }^{8-13}$ Diatomics were inserted into $\mathrm{C}_{60}$ and $\mathrm{C}_{70}$ under high pressures and temperatures. ${ }^{18}$ We have therefore used the examples of $\mathrm{NH}_{3} @ \mathrm{C}_{60}$ and $\mathrm{NH}_{4} @ \mathrm{C}_{60}$ to conduct a purely theoretical study to investigate the possibility of synthesizing endohedral guests within fullerenes by allowing reagents (in this case protons and atomic hydrogens) to pass through the walls of the fullerene. To our knowledge, the only studies in which atoms or ions have passed through the

\footnotetext{
${ }^{a}$ Computer-Chemie-Centrum and Interdisciplinary Center for Molecular Materials, Department of Chemie und Pharmazie, Friedrich-Alexander-Universität Erlangen-Nürnberg, Nägelsbachstr. 25, 91052 Erlangen, Germany. E-mail:Tim.Clark@fau.de

${ }^{b}$ Max-Planck-Institut für Kohlenforschung, Kaiser-Wilhelm-Platz 1, 45470 Mülheim an der Ruhr, Germany. E-mail: dral@kofo.mpg.de

$\dagger$ Electronic supplementary information (ESI) available: Gaussian archives of all optimized structures and MS Excel tables with all energies. See DOI: 10.1039/c7cp02865b
}

fullerene cage wall involve escape or insertion of an endohedral guest. ${ }^{4,25-27}$

Here we investigate the possibility of synthesizing $\mathrm{NH}_{x} @ \mathrm{C}_{60}$

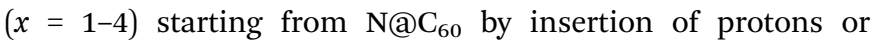
hydrogen atoms through the fullerene wall. $\mathrm{NH}_{3} @ \mathrm{C}_{60}$, for instance, has not yet been observed experimentally, although theoretical studies are available. ${ }^{28-30}$ In 2008 ammonia was inserted into a chemically opened fullerene. ${ }^{31}$ However, the chemical properties of the host-guest complex obtained must differ greatly from the target endofullerene $\mathrm{NH}_{3} @ \mathrm{C}_{60}$, since even at low temperatures $\left(-10^{\circ} \mathrm{C}\right)$ ammonia escapes slowly from this open-cage fullerene. ${ }^{31}$ It is known, however, that $\mathrm{NH}_{3} @ \mathrm{C}_{60}$ is thermodynamically stable, while $n \mathrm{NH}_{3} @ \mathrm{C}_{60}$ with $n=2-7$ represent metastable structures and the cage finally breaks for $n=8 .{ }^{30}$

Scheme 1 shows a suggested synthetic route to $\mathrm{NH}_{3} @ \mathrm{C}_{60}$ and $\mathrm{NH}_{4} @ \mathrm{C}_{60}$ via consecutive pronation and reduction steps starting from the known ${ }^{2-4} \mathrm{~N} @ \mathrm{C}_{60}$, which has been suggested as a possible material for the development of the electron-spin quantum computers. ${ }^{32,33}$ We compare this route to the stepwise direct hydrogenation. Since the spin states of nitrogen hydrides vary with the number of hydrogen atoms, we also investigate all the intermediate $\mathrm{NH}_{x} @ \mathrm{C}_{60}$ compounds for $x=0-4$ as they can be potentially interesting for spintronics applications. In addition, we investigate the electronic properties of $\mathrm{NH}_{4} @ \mathrm{C}_{60}$.

\section{Computational details}

Geometries of all structures were fully optimized at the B3LYP $\mathrm{P}^{34-39}$ level of theory using the $6-31 \mathrm{G}(\mathrm{d})^{40-51}$ basis set (denoted as "B3LYP" in the following). Stationary points were confirmed to be minima or transition states by calculating the vibrational normal modes within the harmonic approximation. One additional spurious imaginary vibrations $\left(-6.3 \mathrm{~cm}^{-1}\right)$ for $\mathbf{T S 1} \mathbf{b}^{+}$was ignored. 


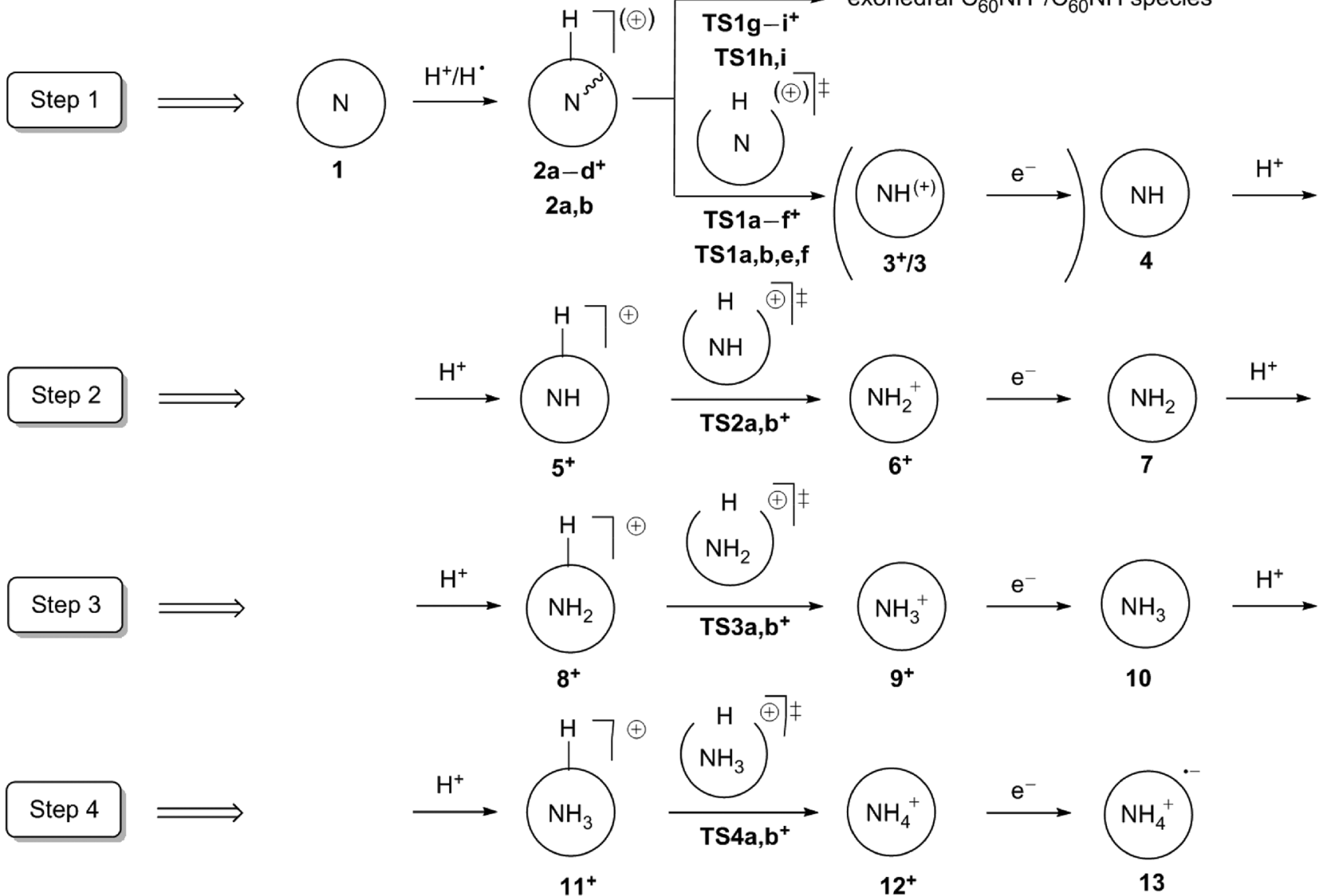

Scheme 1 Proposed approach for step-by-step synthesis of $\mathrm{NH}_{4}{ }^{+} \mathrm{aC}_{60}{ }^{--}$(13). The $\mathrm{C}_{60}$ cage is represented as circles for clarity. Different pathways considered are designated with lower case characters $\mathbf{a}-\mathbf{i}$ (see Results and discussion).

Additional single-point (SP) calculations were performed at the MP2 $2^{52-57}$ level of theory with the same basis set on the DFT-optimized geometries (denoted in the following MP2). All B3LYP/6-31G(d)- and MP2-computed relative energies are corrected for zero-point vibrational energies (ZPEs) calculated at the DFT level. Unrestricted B3LYP calculations were performed for all open-shell systems. However, ROMP2 single points were performed for open-shell systems because of high spin contamination in the unrestricted calculations. All structures were visualised with ChemCraft 1.7. ${ }^{58}$

All Hartree-Fock reference wavefunctions used in RMP2 calculations exhibit RHF/UHF instabilities for the closed-shell systems and the reference UHF wavefunctions have internal instabilities for the open-shell systems. Some, but not all, B3LYP wavefunctions also exhibit instabilities. Wavefunction instabilities cause the large relative energy differences between B3LYP and MP2 calculations in some cases. Thus, the orbital initial guesses for MP2 calculations of the endofullerenes were read from DFT checkpoint files, which lead to the numerically stable and consistent results.
The Gaussian $03^{59}$ and $09^{60}$ program packages were used for all calculations. The key reaction pathways along both directions from the transition structures were followed by the IRC method. ${ }^{61}$ Natural population analysis ${ }^{62-68}$ (NPA) was performed within the Gaussian 03 and 09 packages using the density matrices for the current methods. $^{69}$

\section{Results and discussion}

\section{Mechanism of proton penetration and nitrogen escape}

Our calculations start from the appropriate exo-protonated $\mathrm{NH}_{x-1} @ \mathrm{C}_{60}$ endofullerenes and proceed according to Scheme 1. Any study of these systems is complicated by their many possible spin states. Thus, the first reaction step (step 1 in Scheme 1) begins from $\mathrm{N} @ \mathrm{C}_{60}$ 1, which can exist in high- (spin 3/2) and low-spin (spin 1/2) states. It has been shown in previous experimental $^{2,70-72}$ and theoretical ${ }^{4,73,74}$ studies that the ground state of $\mathbf{1}$ is high spin. Our current study supports this conclusion, since ${ }^{4} \mathbf{1}$ is more stable than ${ }^{2} \mathbf{1}$ (see Scheme 2) by $26.0 \mathrm{kcal} \mathrm{mol}^{-1}$ 


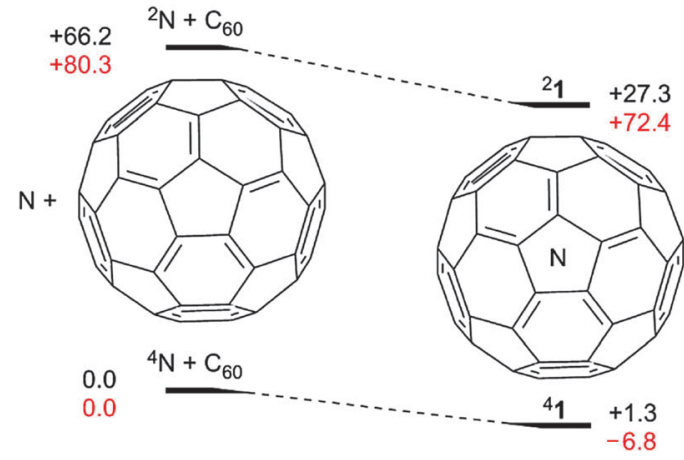

Scheme 2 Schematic energy profile for $\mathrm{N}$ insertion into $\mathrm{C}_{60}$, relative energies in $\mathrm{kcal} \mathrm{mol}^{-1}$ at the B3LYP (black) and MP2 (red) levels.

and $79.2 \mathrm{kcal} \mathrm{mol}^{-1}$ at the B3LYP and MP2 levels, respectively. Moreover, although the formation of ${ }^{4} \mathbf{1}$ from a free nitrogen atom and $\mathrm{C}_{60}$ is found to be slightly endothermic (by $1.3 \mathrm{kcal} \mathrm{mol}^{-1}$ ) at the B3LYP level, earlier UB3LYP/D95*//PM3 calculations, ${ }^{4}$ found it to be exothermic by $0.9 \mathrm{kcal} \mathrm{mol}^{-1}$ and our MP2 calculations predict the formation of ${ }^{4} \mathrm{~N} @ \mathrm{C}_{60}$ to be favorable by $-6.8 \mathrm{kcal} \mathrm{mol}^{-1}$. Thus, our further discussion of step 1 (Scheme 1) will be concerned with the quartet potential-energy surface (PES).

Several possible pathways exist between the exo-protonated ${ }^{4} \mathrm{~N} @ \mathrm{C}_{60} \mathrm{H}^{+} \mathbf{2 a}^{+}$(Fig. 1) and $\mathrm{NH}^{+} @ \mathrm{C}_{60} 3^{+}$. We will therefore discuss step 1 (Scheme 1) in detail and steps 2-4 more briefly, since they are quite similar. As expected, the exo-protonation step $(\mathbf{1}+$ $\left.\mathrm{H}^{+} \rightarrow 2 \mathrm{a}^{+}\right)$is highly exothermic $\left(-211.1\right.$ and $-196.3 \mathrm{kcal} \mathrm{mol}^{-1}$ at B3LYP and MP2, respectively). The ${ }^{4} \mathbf{2 a}^{+} /{ }^{2} \mathbf{2 a ^ { + }}$ gap is only slightly
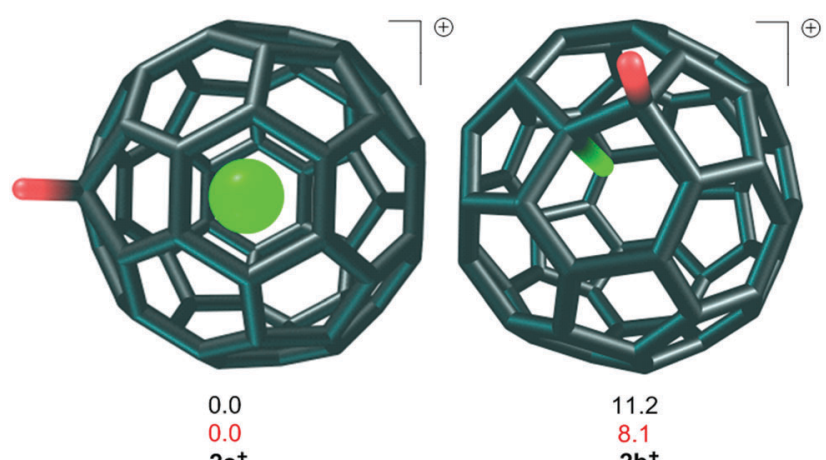

$2 a^{+}$

$2 b^{+}$

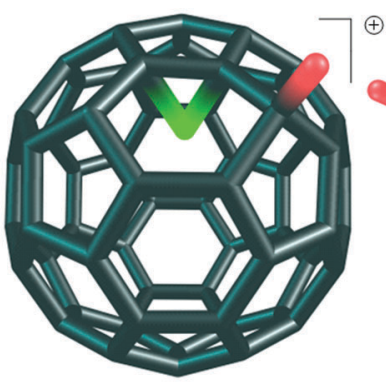

18.7

28.7

$2 c^{+}$

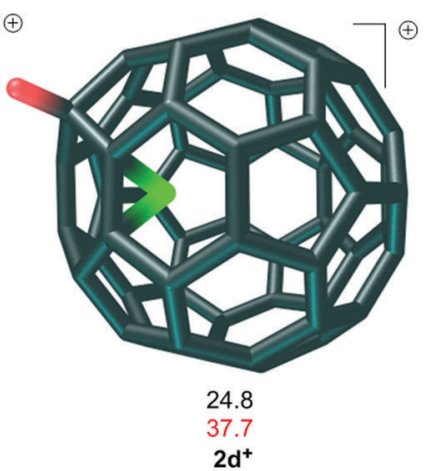

Fig. 1 Structures and relative energies in $\mathrm{kcal} \mathrm{mol}^{-1}$ at the B3LYP (black) and MP2 (red) levels for the quartet minima $\mathbf{2} \mathbf{a}-\mathbf{d}^{+}$ smaller than for ${ }^{4} \mathbf{1} / /^{2} \mathbf{1}$ (24.9 and $78.2 \mathrm{kcal} \mathrm{mol}^{-1}$ at B3LYP and MP2, respectively).

Starting from $2 \mathrm{a}^{+}$, the proton can reach the nitrogen atom by breaking either a $[5,6]$ - or a $[6,6]$-bond of $\mathrm{C}_{60}\left(\mathrm{TS1a}^{+}\right.$and $\mathbf{T S 1}^{+}$, respectively, Fig. 2). The more favorable of these two transition states is ${ }^{4} \mathbf{T S 1 a}^{+}$for migration by breaking a [5,6]-bond, with calculated barriers of 90.0 and $90.1 \mathrm{kcal} \mathrm{mol}^{-1}$ relative to ${ }^{4} \mathbf{2 a}^{+}$at the B3LYP and MP2 levels, respectively. No pathways that involve direct passage of the proton through the hexagonal or pentagonal rings were found. An attempted transition-state optimization for the first case without symmetry constraints

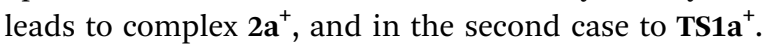

In addition, a previous DFT study of proton migration on the $\mathrm{C}_{60}$ surface, ${ }^{75}$ which should behave very similarly to that on the surface of $\mathrm{NH}_{x} @ \mathrm{C}_{60} \mathrm{H}^{+}$, showed that transition states in which the proton lies above the centers of five- or six-membered rings are those for proton migration over the $\mathrm{C}_{60}$ surface. Nevertheless, transition states for these two processes were computed using symmetry constraints and found to be highly unfavorable relative to proton migration above $[5,6]$ - and $[6,6]$-bonds. $^{75}$

A mechanism analogous to He-insertion into $\mathrm{C}_{60}$, which occurs through a "window" made by opening two $\mathrm{C}-\mathrm{C}$ bonds, ${ }^{27}$ was also considered. However, the transition state for this process, ${ }^{4} \mathbf{T S 1 c}^{+}$ lies much higher in energy than ${ }^{4} \mathbf{T S 1 a}, \mathbf{b}^{+}$(Fig. 2). Another study ${ }^{25}$ suggested that the most favorable pathway of He-insertion should be to open a window by breaking three-bonds. However, we found that the transition state for this process, ${ }^{4} \mathbf{T S} \mathbf{d}^{+}$is the least favorable of those studied here.

In addition to the pathways discussed above (Fig. 2), we have also considered possible lower-lying ones that occur via the formation of endo- $\mathrm{NH}_{x} @ \mathrm{C}_{60} \mathrm{H}^{+}$intermediates at $[5,6]$ - and $[6,6]$ aza bridges. Protonating the $\mathrm{C}_{60}$ cage causes a drastic increase in the number of possible isomeric endofullerenes with aza-bridges. However, due to the stabilizing interaction between the nitrogen lone pair and the positively charged carbon atoms adjacent to the $\mathrm{C}-\mathrm{H}$ moiety, the three endo- $\mathrm{N} @ \mathrm{C}_{60} \mathrm{H}^{+}$isomers $2 \mathbf{b}-\mathbf{d}^{+}$shown in Fig. 2 are expected to be the most favorable. This was confirmed partially by calculating two other endo- $\mathrm{N} @ \mathrm{C}_{60} \mathrm{H}^{+}$isomers in which the nitrogen atom is farthest from the $\mathrm{C}-\mathrm{H}$ moiety. $\mathbf{2} \mathbf{b}^{+}$is the most stable endo-N@ $\mathrm{C}_{60} \mathrm{H}^{+}$isomer, but the nitrogen atom does not form an aza-bridge and is rather covalently bound to one carbon atom (denoted "endohedrally bound" below) with a $\mathrm{C}-\mathrm{N}$ bond length of $1.53 \AA$ A. The nitrogen atom has a negative charge of $-0.136 e$ according to an NPA analysis. $2 \mathbf{b}^{+}$can be formed with a relatively low barrier $\left(\mathbf{T S 1 g}^{+}, 19.4\right.$ and $30.1 \mathrm{kcal} \mathrm{mol}^{-1}$, at the B3LYP and MP2 levels, respectively, Fig. 2) from $2 \mathbf{a}^{+}$. This barrier is much lower than that found for $\mathrm{N} @ \mathrm{C}_{60}{ }^{4}$ because of the interaction of the nitrogen lone pair with the protonated $\mathrm{C}_{60}$ cage.

Analogously to $\mathbf{T S 1 a}^{+}$and $\mathbf{T S 1}^{+}$, we found $\mathbf{T S 1 e}^{+}$and $\mathbf{T S 1 f}^{+}$, which correspond to the transition states for the reaction paths starting from $\mathbf{2} \mathbf{b}^{+}$, in which the proton is inserted through the [5,6]- and [6,6]-bonds, respectively. However, they lie too high in energy to play a role in the reaction (Fig. 2). In contrast, $\mathrm{N}$-escape becomes possible from the $2 \mathbf{b}^{+}$intermediate through both the $[5,6]$ - and $[6,6]$-bonds $\left(\mathbf{T S}_{\mathbf{h}}{ }^{+}\right.$and $\mathbf{T S} 1 \mathbf{i}^{+}$, respectively). The latter is more favorable, as also found for $\mathrm{N} @ \mathrm{C}_{60} \cdot{ }^{4} \mathbf{T S 1 i}^{+}$ 

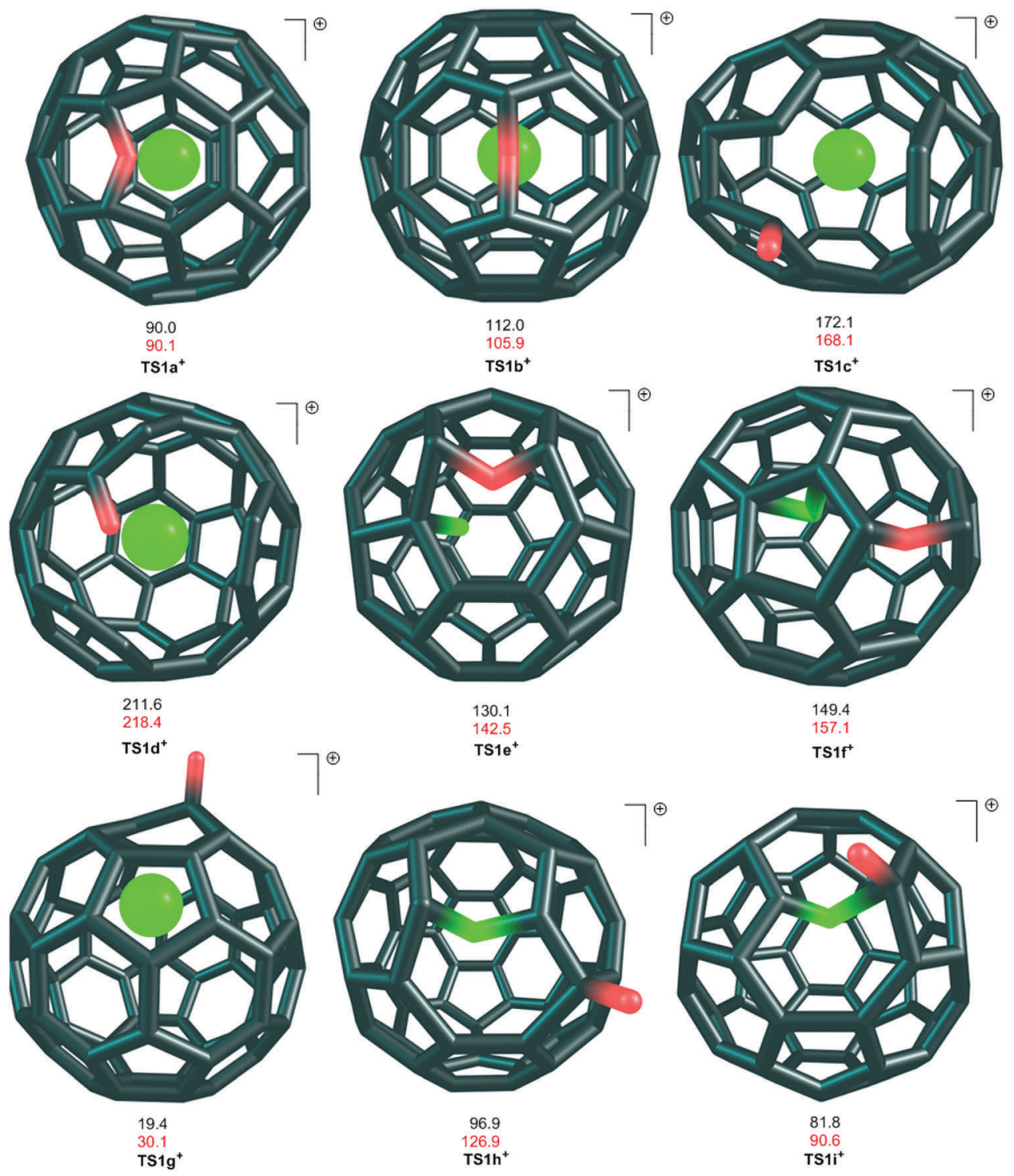

Fig. 2 Structures and energies relative to $2 \mathrm{a}^{+}$in $\mathrm{kcal} \mathrm{mol}{ }^{-1}$ at the B3LYP (black) and MP2 (red) levels for proton migration from $2 a-\mathbf{d}^{+}$to $\mathbf{3}^{+}$via the alternative quartet transition states TS1a- $\mathbf{f}^{+}$, and for the $\mathrm{N}$-escape from $\mathbf{2} \mathbf{b}-\mathbf{d}^{+}$via alternative quartet transition states TS1 $\mathbf{h}^{+}$by breaking a $[5,6]-$ bond and

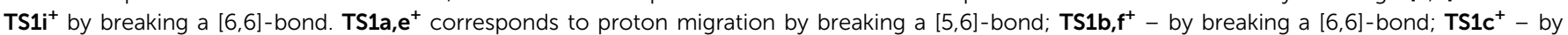
breaking two bonds and $\mathbf{T S} 1 \mathbf{d}^{+}$by breaking three bonds. $\mathbf{T S} \mathbf{g}^{+}$corresponds to the formation of $\mathbf{2 b}^{+}$from $\mathbf{2 \mathbf { a } ^ { + }}$.

lies $81.8 \mathrm{kcal} \mathrm{mol}^{-1}$ higher in energy than $2 \mathrm{a}^{+}$on the PES at the B3LYP level and thus lower than $\mathbf{T S 1 a}^{+}\left(90.0 \mathrm{kcal} \mathrm{mol}^{-1}\right)$. However, at the MP2 level, this ordering is reversed: $\mathbf{T S}^{+} \mathrm{i}^{+}$lies slightly higher in energy than TS1a $^{+}\left(90.6\right.$ vs. $90.1 \mathrm{kcal} \mathrm{mol}^{-1}$ ). Thus, nitrogen escape and nitrogen protonation can be competitive processes.

We only considered insertion pathways through the $[5,6]$ - and $[6,6]$-bonds via transition states of the types $\mathbf{T S}^{+}{ }^{+}$and $\mathbf{T S}^{+} \mathbf{b}^{+}$, respectively, for the subsequent steps $2-4$ (Scheme 1). These pathways are the most favorable for step 1 and the remaining steps appear to be very similar in geometries and barriers heights (see below). The designations $\mathbf{a}$ and $\mathbf{b}$ used for transition states TS2 $^{+}-$TS4 $^{+}$have the same meaning as for the transition states, $\mathrm{TS}^{+}$, for the first step. No stable minima were found for endo$\mathrm{NH} @ \mathrm{C}_{60}$ in which $\mathrm{NH}$ forms aza-bridges to a nearby $\mathrm{C}-\mathrm{H}$ moiety.
All such starting geometries optimized to $\mathrm{NH} @ \mathrm{C}_{60} \mathrm{H}^{+}$with $\mathrm{NH}$ at the center of the $\mathrm{C}_{60}$ cage. We therefore did not investigate pathways for further protonation of the nitrogen-containing moiety via endo- $\mathrm{NH}_{x} @ \mathrm{C}_{60} \mathrm{H}^{+}$intermediates for steps 2-4.

\section{Energetics of the step-by-step formation of $\mathrm{NH}_{4}{ }^{+} @ \mathrm{C}_{60}{ }^{\cdot-}$}

The energetics of all four steps shown in Scheme 1 are given in Table 1 and in Scheme 3, where energies relative to ${ }^{4} 2 \mathbf{a}^{+}$and relative energies within a step are shown. All reactions are exothermic, by 7-56 kcal mol ${ }^{-1}$ at B3LYP and by 18-109 $\mathrm{kcal} \mathrm{mol}^{-1}$ at MP2.

The barriers for each type of pathway hardly vary for the different steps and multiplicities. Thus, for step 1 the doublet PES lies almost parallel to the quartet one. Since doublet $2 \mathrm{a}^{+}$ lies higher in energy than quartet $2 \mathbf{a}^{+}$, and $\mathbf{1}$ exists in the 
Table 1 Energetics of the four-step synthesis of $\mathrm{NH}_{4}{ }^{+} \mathrm{aC}_{60^{\circ}}{ }^{-1}$

\begin{tabular}{|c|c|c|c|c|}
\hline \multirow[b]{2}{*}{ Structure } & \multicolumn{2}{|l|}{ B3LYP } & \multicolumn{2}{|l|}{ MP2 } \\
\hline & $\begin{array}{l}\text { Within a step, } \\
\mathrm{kcal} \mathrm{mol}^{-1}\end{array}$ & $\begin{array}{l}\text { vs. }{ }^{4} \mathbf{2}^{+}, \\
\text {kcal } \mathrm{mol}^{-1}\end{array}$ & $\begin{array}{l}\text { Within a step, } \\
\mathrm{kcal} \mathrm{mol}^{-1}\end{array}$ & $\begin{array}{l}\text { vs. }{ }^{4} \mathbf{2}^{+}, \\
\text {kcal } \mathrm{mol}^{-1}\end{array}$ \\
\hline \multicolumn{5}{|c|}{ Step 1} \\
\hline \multicolumn{5}{|c|}{ Quartet PES } \\
\hline${ }^{4} 2 a+$ & 0.0 & & 0.0 & \\
\hline${ }^{4} 2 \mathbf{b}^{+}$ & 11.2 & & 8.1 & \\
\hline${ }^{4} \mathrm{c}^{+}$ & 18.7 & & 28.7 & \\
\hline${ }^{4} 2 \mathrm{~d}+$ & 24.8 & & 37.7 & \\
\hline${ }^{4} \mathrm{TS} \mathrm{C}^{+}$ & 90.0 & & 90.1 & \\
\hline${ }^{4} \mathbf{T S}_{\mathbf{b}} \mathbf{b}^{+}$ & 112.0 & & 105.9 & \\
\hline${ }^{4}$ TS1c $^{+}$ & 172.1 & & 168.1 & \\
\hline${ }^{4}$ TS1d $^{+}$ & 211.6 & & 218.4 & \\
\hline${ }^{4} \mathbf{T S}_{\mathrm{e}}{ }^{+}$ & 130.1 & & 142.5 & \\
\hline${ }^{4} \mathbf{T S 1 f}^{+}$ & 149.4 & & 157.1 & \\
\hline${ }^{4} \mathrm{TS} \mathrm{g}^{+}$ & 19.4 & & 30.1 & \\
\hline${ }^{4} \mathbf{T S} \mathbf{h}^{+}$ & 96.9 & & 126.9 & \\
\hline${ }^{4} \mathbf{T S}_{1}{ }^{+}$ & 81.8 & & 90.6 & \\
\hline${ }^{4} 3^{+}$ & -17.8 & & -25.5 & \\
\hline${ }^{5} 4^{a}$ & -144.7 & & -158.9 & \\
\hline $4^{a}$ & -181.6 & & -179.8 & \\
\hline${ }^{1} 4^{a}$ & -130.3 & & -122.9 & \\
\hline \multicolumn{5}{|c|}{ Doublet PES } \\
\hline${ }^{2} \mathbf{2 a}^{+}$ & 0.0 & 24.9 & 0.0 & 78.2 \\
\hline${ }^{2} \mathrm{TS} \mathrm{a}^{+}$ & 90.2 & 115.1 & 89.9 & 168.0 \\
\hline${ }^{2}$ TS1b $^{+}$ & 112.2 & 137.1 & 107.7 & 185.9 \\
\hline${ }^{2} 3^{+}$ & -43.9 & -19.0 & -46.6 & 31.5 \\
\hline \multicolumn{5}{|c|}{ Step 2 (triplet PES) } \\
\hline${ }^{3} 5^{+}$ & 0.0 & -393.9 & 0.0 & -376.9 \\
\hline${ }^{3}$ TS2 $^{+}{ }^{+}$ & 90.9 & -303.0 & 91.4 & -285.5 \\
\hline${ }^{3} \mathbf{T S}_{2} \mathbf{b}^{+}$ & 112.2 & -281.7 & 109.5 & -267.4 \\
\hline${ }^{3} 6^{+}$ & -26.4 & -420.3 & -37.1 & -414.0 \\
\hline${ }^{2} 7$ & -188.4 & -582.3 & -194.2 & -571.1 \\
\hline \multicolumn{5}{|c|}{ Step 3 (doublet PES) } \\
\hline${ }^{2} 8^{+}$ & 0.0 & -794.0 & 0.0 & -767.9 \\
\hline${ }^{2}$ TS33a $^{+}$ & 87.5 & -706.5 & 88.3 & -679.6 \\
\hline${ }^{2} \mathbf{T S} 3 \mathbf{b}^{+}$ & 110.8 & -683.2 & 104.2 & -663.7 \\
\hline${ }^{2} 9^{+}$ & -38.0 & -832.0 & -54.2 & -822.1 \\
\hline${ }^{1} 10$ & -201.9 & -995.9 & -212.9 & -980.8 \\
\hline \multicolumn{5}{|c|}{ Step 4 (singlet PES) } \\
\hline${ }^{1} \mathbf{1 1}^{+}$ & 0.0 & -1208.7 & 0.0 & -1178.6 \\
\hline${ }^{1}$ TS4 $^{+}{ }^{+}$ & 89.1 & -1119.6 & 90.2 & -1088.4 \\
\hline${ }^{1}$ TS4 $^{+}{ }^{+}$ & 112.0 & -1096.7 & 108.6 & -1070.0 \\
\hline${ }^{1} 12^{+}$ & -6.8 & -1215.5 & -17.8 & -1196.4 \\
\hline${ }^{2} 13$ & -135.2 & -1343.9 & -155.7 & -1334.3 \\
\hline
\end{tabular}

quartet state (see above) the entire reaction most likely proceeds on the quartet PES. Similarly, the second step should proceed on the triplet, rather than on the singlet or quintet PES, because $\mathbf{4}^{+}$is by far most stable in the triplet state (Table 1 ).

The endofullerenes $\mathrm{NH}_{x}^{+} @ \mathrm{C}_{60}$ all have high electron affinities (from 111 to $164 \mathrm{kcal} \mathrm{mol}^{-1}(4.83-7.11 \mathrm{eV}$ ) at B3LYP and from 97 to $211 \mathrm{kcal} \mathrm{mol}^{-1}(4.23-9.16 \mathrm{eV})$ at MP2, Table 2) and thus they can be readily reduced to the neutral endofullerenes $\mathrm{NH}_{x} @ \mathrm{C}_{60}$, e.g. using gas-phase neutralization as has been demonstrated for other endofullerenes. ${ }^{11,12}$

The total energy gain of all transformations starting from 1 and ending with 13 according to eqn (1) is $1555.0 \mathrm{kcal} \mathrm{mol}^{-1}$ at B3LYP and $1530.6 \mathrm{kcal} \mathrm{mol}^{-1}$ at MP2.

$$
\mathrm{N} @ \mathrm{C}_{60}+4 \mathrm{H}^{+}+4 e^{-} \rightarrow \mathrm{NH}_{4}^{+} @ \mathrm{C}_{60}{ }^{\bullet-}
$$

Although the barriers for protonating endohedral nitrogen hydrides through the fullerene cage are too high to be observable in solution, the entire process involves a continuous decrease in energy, so that each step is possible in the gas phase. The calculated proton affinities of $\mathrm{NH}_{x} @ \mathrm{C}_{60}$ in the gas phase (Table 3) are very similar to that of $\mathrm{C}_{60}$ itself $\left(211\right.$ and $196 \mathrm{kcal} \mathrm{mol}^{-1}$ at the B3LYP and MP2 levels of theory, respectively, compared with the experimental range $\mathrm{e}^{76}$ of 204 to $207 \mathrm{kcal} \mathrm{mol}^{-1}$ and a further calculated value $\mathrm{e}^{75}$ of $202 \mathrm{kcal} \mathrm{mol}^{-1}$ ). The calculated proton affinities for the endohedral nitrogen-containing species lie in the range between 207 and $213 \mathrm{kcal} \mathrm{mol}^{-1}$ with B3LYP and between 194 and $198 \mathrm{kcal} \mathrm{mol}^{-1}$ with MP2.

Thus, the protonated species $\mathrm{NH}_{x} @ \mathrm{C}_{60} \mathrm{H}^{+}$possess adequate energy immediately after their formation to cross the calculated barriers for protonation through the $\mathrm{C}_{60}$ cage. Therefore, a protonation-rearrangement cascade from $\mathrm{NH}_{x-1} @ \mathrm{C}_{60}$ to $\mathrm{NH}_{x}^{+} @ \mathrm{C}_{60}$ is possible. However, as the rearrangements to $\mathrm{NH}_{x}{ }^{+} @ \mathrm{C}_{60}$ are mildly exothermic, the product is even hotter than the protonated fullerene precursor, so that thermal energy would have to be dissipated at the product stage. Using less energy-rich acids such as $\mathrm{H}_{3}{ }^{+}$and $\mathrm{CH}_{5}{ }^{+}$, which are common protonating agents in ion cyclotron resonance spectrometry, ${ }^{77-79}$ would render the initial proton transfer to $\mathrm{NH}_{x} @ \mathrm{C}_{60}$ less exothermic. The relevant heats of reaction are shown in Table 3. Generally, the energy gained from protonation by $\mathrm{CH}_{5}{ }^{+}$is slightly less than the barriers for transferring the proton through the cage to nitrogen. On the other hand, proton transfer from $\mathrm{H}_{3}{ }^{+}$releases slightly more energy than is necessary to overcome the barrier. Thus, $\mathrm{H}_{3}{ }^{+}$is a promising candidate for the individual through-cage protonation steps.

\section{Alternative approach using hydrogenation by hydrogen atoms}

In addition, we considered the corresponding hydrogenation of nitrogen inside $\mathrm{C}_{60} 1$ through the buckminsterfullerene wall by atomic $\mathrm{H}^{\bullet}$ to compare barriers with those described above for protonation by the bare proton $\mathrm{H}^{+}$(Scheme 1 ). Three possible spin states (quintet, triplet and singlet) were taken into account. The energetics of the computed pathway are summarized in Table 4. Notations of species are the same as above with the difference that all further discussion will refer to neutral species rather than positively charged ones.

Unlike $2 \mathrm{a}^{+}$with nitrogen located at the center of the protonated $\mathrm{C}_{60}$ cage (Fig. 2), neutral $\mathrm{N} @ \mathrm{C}_{60} \mathrm{H}$ 2a is not the most stable isomer. The most favorable one is singlet $2 \mathrm{e}$ (Table 4 and Fig. 3 ). In $2 \mathrm{e}$ nitrogen forms covalent bonds with three neighboring carbons of a hexagon and the fourth carbon is saturated with hydrogen atom. Such a structure is so strongly preferred for the singlet state that no $\mathbf{2 b}$ can be located: any attempts to find $\mathbf{2 b}$ end in $2 \mathbf{e}$.

Moreover, ${ }^{1} \mathbf{2 e}$ is closely followed in energy by the most stable triplet isomer of $\mathbf{2}$ (2b) and by quintet $\mathbf{2 a}$ (Fig. 3), which are less favorable by 0.1 and $2.2 \mathrm{kcal} \mathrm{mol}^{-1}$ at DFT and by 8.1 and $5.9 \mathrm{kcal} \mathrm{mol}^{-1}$ at MP2, respectively. Thus, the higher spin state, the lower ability of nitrogen to form covalent bonds with the inner surface of $\mathrm{C}_{60}$ cage. This can be seen clearly from 


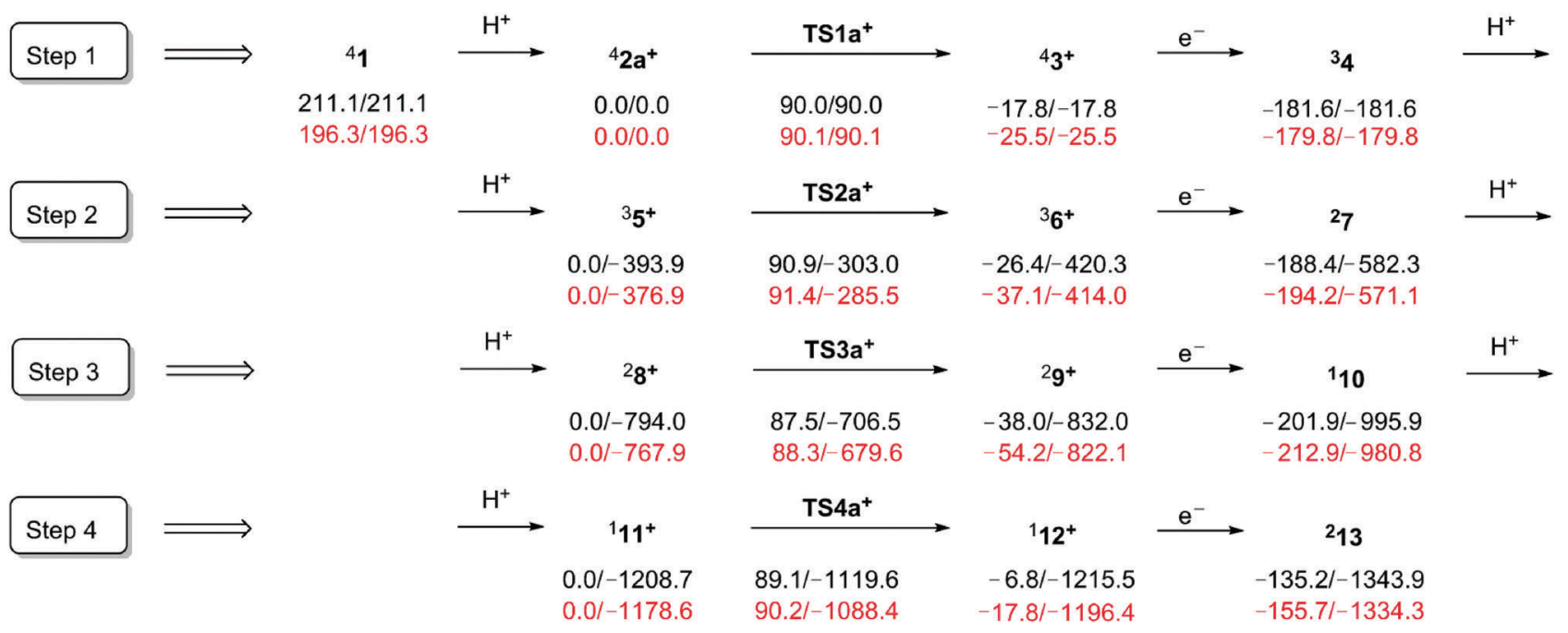

Scheme 3 Energetics of the four-step synthesis of $\mathrm{NH}_{4}{ }^{+}{\left(\mathrm{aC}_{60}\right.}^{--} 13$ via the most favorable transition states and spin states. Energies in $\mathrm{kcal}^{-1} \mathrm{~mol}^{-1}$ within a step vs. (/) relative to ${ }^{4} \mathbf{2} \mathrm{a}^{+}$at the B3LYP (black) and at the MP2 (red).

Table 2 Electron affinities of the species $\mathrm{NH}_{x}^{+}\left(\mathrm{aC}_{60}, x=1-4\left(3^{+}, \mathbf{6}^{+}, \mathbf{9}^{+}\right.\right.$ and $12^{+}$, respectively)

\begin{tabular}{|c|c|c|c|c|c|}
\hline \multirow{2}{*}{$\begin{array}{l}\text { Oxidized } \\
\text { species }\end{array}$} & \multirow{2}{*}{$\begin{array}{l}\text { Reduced } \\
\text { species }\end{array}$} & \multicolumn{2}{|l|}{ B3LYP } & \multicolumn{2}{|l|}{ MP2 } \\
\hline & & $\mathrm{kcal} \mathrm{mol}^{-1}$ & $\mathrm{eV}$ & $\mathrm{kcal} \mathrm{mol}^{-1}$ & $\mathrm{eV}$ \\
\hline \multirow[t]{3}{*}{$\begin{array}{l}\text { Step } 1 \\
{ }^{4} 3^{+}\end{array}$} & ${ }^{5} 4$ & 126.9 & 5.50 & 133.4 & 5.78 \\
\hline & ${ }^{3} 4$ & 163.8 & 7.10 & 154.3 & 6.69 \\
\hline & ${ }^{1} 4$ & 112.6 & 4.88 & 97.4 & 4.23 \\
\hline \multirow[t]{3}{*}{${ }^{2} 3^{+}$} & ${ }^{5} 4$ & 125.7 & 5.45 & 190.4 & 8.26 \\
\hline & ${ }^{3} 4$ & 162.6 & 7.05 & 211.3 & 9.16 \\
\hline & ${ }^{1} 4$ & 111.3 & 4.83 & 154.5 & 6.70 \\
\hline \multicolumn{6}{|l|}{ Step 2} \\
\hline${ }^{3} 6^{+}$ & ${ }^{2} 7$ & 161.9 & 7.02 & 157.1 & 6.81 \\
\hline \multicolumn{6}{|l|}{ Step 3} \\
\hline${ }^{2} 9^{+}$ & ${ }^{1} 10$ & 163.9 & 7.11 & 158.7 & 6.88 \\
\hline $\begin{array}{l}\text { Step } 4 \\
\mathbf{1}_{12^{+}}\end{array}$ & ${ }^{2} 13$ & 128.4 & 5.57 & 1370 & 509 \\
\hline
\end{tabular}

the geometries of ${ }^{5} \mathbf{2 a},{ }^{1} \mathbf{2 e}$ and ${ }^{3} \mathbf{2 b}$ (Fig. 3): nitrogen is located at the center of the $\mathrm{C}_{60}$ cage for the quintet $\mathbf{2 a}$, it is covalently bound with only one carbon atom in triplet $\mathbf{2 b}$ and with three carbon atoms in singlet $2 \mathbf{e}$.

In contrast to the protonation, nitrogen escape appears to be more favorable than hydrogen insertion through the $\mathrm{C}_{60}$ cage for all spin states (Table 4 and Fig. 3). The most favorable transition state is singlet TS1i, i.e. nitrogen escape via breaking the $[6,6]$-bond (Fig. 3). The barrier to this escape is 69.4 and $80.5 \mathrm{kcal} \mathrm{mol}^{-1}$ at DFT and MP2, respectively. N-escape through a [5,6]-bond breaking via ${ }^{1} \mathbf{T S 1 h}$ is less than $2 \mathrm{kcal} \mathrm{mol}^{-1}$ higher in energy. Nitrogen escape for the triplet and quintet PESs proceeds via the corresponding TS1i with barriers of 76.9 an $95.9 \mathrm{kcal} \mathrm{mol}^{-1}$ at DFT and of 81.0 and $98.8 \mathrm{kcal} \mathrm{mol}^{-1}$ at MP2, respectively. They are followed up by the TS1m, in which nitrogen displaces the carbon atom (Fig. 3).
Table 3 Energetics of protonation of the species $\mathrm{NH}_{x} @ \mathrm{CC}_{60}, x=0-3(\mathbf{1}, \mathbf{4}$, 7 and 10 , respectively) and of the proton transfer to them from the proton carriers $\mathrm{H}_{3}^{+}$and $\mathrm{CH}_{5}{ }^{+}$in $\mathrm{kcal} \mathrm{mol}{ }^{-1}$

\begin{tabular}{|c|c|c|c|c|}
\hline \multirow[b]{2}{*}{ Reaction } & \multicolumn{2}{|l|}{ B3LYP } & \multicolumn{2}{|l|}{ MP2 } \\
\hline & Quartet & Doublet & Quartet & Doublet \\
\hline \multicolumn{5}{|l|}{ Step 1} \\
\hline $\mathbf{1}+\mathrm{H}^{+} \rightarrow 2 \mathrm{a}^{+}$ & -211.1 & -212.2 & -196.3 & -197.4 \\
\hline $\mathbf{1}+\mathrm{H}_{3}^{+} \rightarrow 2 \mathrm{a}^{+}+\mathrm{H}_{2}$ & -121.8 & -122.8 & -107.5 & -108.5 \\
\hline $1+\mathrm{CH}_{5}^{+} \rightarrow 2 \mathrm{a}^{+}+\mathrm{CH}_{4}$ & -85.7 & -86.8 & -74.9 & -75.9 \\
\hline \multicolumn{5}{|l|}{ Step 2 (triplet PES) } \\
\hline $4+\mathrm{H}^{+} \rightarrow 5^{+}$ & -212.3 & & -197.1 & \\
\hline $4+\mathrm{H}_{3}^{+} \rightarrow 5^{+}+\mathrm{H}_{2}$ & -123.0 & & -108.2 & \\
\hline $4+\mathrm{CH}_{5}^{+} \rightarrow 5^{+}+\mathrm{CH}_{4}$ & -86.9 & & -75.6 & \\
\hline \multicolumn{5}{|l|}{ Step 3 (doublet PES) } \\
\hline $7+\mathrm{H}^{+} \rightarrow 8^{+}$ & -211.7 & & -196.8 & \\
\hline $7+\mathrm{H}_{3}^{+} \rightarrow 8^{+}+\mathrm{H}_{2}$ & -122.4 & & -108.0 & \\
\hline $7+\mathrm{CH}_{5}^{+} \rightarrow \mathbf{8}^{+}+\mathrm{CH}_{4}$ & -86.3 & & -75.4 & \\
\hline \multicolumn{5}{|l|}{ Step 4 (singlet PES) } \\
\hline $\mathbf{1 0}+\mathrm{H}^{+} \rightarrow \mathbf{1 1}^{+}$ & -212.9 & & -197.7 & \\
\hline $10+\mathrm{H}_{3}^{+} \rightarrow \mathbf{1 1}^{+}+\mathrm{H}_{2}$ & -123.5 & & -108.9 & \\
\hline $10+\mathrm{CH}_{5}^{+} \rightarrow \mathbf{1 1}^{+}+\mathrm{CH}_{4}$ & -87.5 & & -76.3 & \\
\hline
\end{tabular}

Hydrogen penetration through the cage on the singlet PES is highly unfavorable. Moreover, as in the case of minimum ${ }^{1} \mathbf{2 e}$, nitrogen covalent bonding to carbons is so strong that no ${ }^{1} \mathbf{T S 1 a}, \mathbf{b}$ were found. ${ }^{1} \mathbf{T S} 1 \mathbf{j}$ and ${ }^{1} \mathbf{T S 1 k}$ (Fig. 3) were located instead and rather than ${ }^{1}$ TS1e,f. The TSs for hydrogenation of nitrogen through the fullerene cage for triplet and quintet PESs are similar to those for protonation, i.e. TS1a,b,e,f were found. However, hydrogenation of the $\mathrm{N}$-atom is less favorable than $\mathrm{N}$-escape for the triplet PES by 25.7 and $54.2 \mathrm{kcal} \mathrm{mol}^{-1}$ at DFT and MP2, respectively. Nevertheless, barriers of hydrogenation and N-escape are much closer in energy for the quintet PES: hydrogenation is less favorable by 5.0 and $2.0 \mathrm{kcal} \mathrm{mol}^{-1}$ at DFT and MP2, respectively.

The reaction ${ }^{1} \mathbf{2} \mathrm{e} \rightarrow{ }^{1} \mathbf{4}$ is endothermic by 16.4 and $25.5 \mathrm{kcal} \mathrm{mol}^{-1}$, while ${ }^{3} \mathbf{2 b} \rightarrow{ }^{3} \mathbf{4}$ is exothermic by 35.2 and 
Table 4 Energetics of the formation of $\mathrm{NH} \mathrm{CC}_{60} 4$

\begin{tabular}{|c|c|c|c|c|}
\hline \multirow[b]{2}{*}{ Structure } & \multicolumn{2}{|l|}{ B3LYP } & \multicolumn{2}{|l|}{ MP2 } \\
\hline & $\begin{array}{l}\text { Within a step, } \\
\mathrm{kcal} \mathrm{mol}^{-1}\end{array}$ & $\begin{array}{l}\text { vs. }{ }^{1} \mathbf{2 e}, \\
\text { kcal } \mathrm{mol}^{-1}\end{array}$ & $\begin{array}{l}\text { Within a step, } \\
\mathrm{kcal} \mathrm{mol}^{-1}\end{array}$ & $\begin{array}{l}\text { vs. }{ }^{1} \mathbf{2} \mathbf{e}, \\
\text { kcal } \mathrm{mol}^{-1}\end{array}$ \\
\hline \multicolumn{5}{|c|}{ Quintet PES } \\
\hline${ }^{5} \mathbf{a}$ & 0.0 & 2.2 & 0 & 5.9 \\
\hline${ }^{5} 2 b$ & 29.2 & 31.4 & 31.7 & 37.5 \\
\hline${ }^{5}$ TS1a & 100.9 & 103.0 & 100.8 & 106.6 \\
\hline${ }^{5}$ TS1b & 106.8 & 108.9 & 100.1 & 106.0 \\
\hline${ }^{5}$ TS1e & 141.6 & 143.7 & 161.4 & 167.3 \\
\hline${ }^{5}$ TS1f & 152.5 & 154.7 & 171.9 & 177.8 \\
\hline${ }^{5}$ TS1m $^{a}$ & 98.3 & 100.5 & 123.1 & 128.9 \\
\hline${ }^{5}$ TS1i & 95.9 & 98.1 & 98.8 & 104.7 \\
\hline${ }^{5} 4$ & -0.1 & 2.1 & -16.3 & -10.4 \\
\hline \multicolumn{5}{|c|}{ Triplet PES } \\
\hline${ }^{3} 2 a$ & 1.6 & 2.1 & 76.5 & 84.7 \\
\hline${ }^{3} 2 b$ & 0.0 & 0.4 & 0.0 & 8.1 \\
\hline${ }^{3}$ TS1a & 102.6 & 103.0 & 172.6 & 180.7 \\
\hline${ }^{3}$ TS1b & 108.5 & 108.9 & 146.9 & 155.0 \\
\hline${ }^{3}$ TS1e & 125.8 & 126.3 & 135.2 & 143.3 \\
\hline${ }^{3}$ TS1f & 135.1 & 108.9 & 156.0 & 164.1 \\
\hline${ }^{3}$ TS1m $^{a}$ & 81.8 & 82.2 & 96.6 & 104.8 \\
\hline${ }^{3}$ TS1i & 76.9 & 77.4 & 81.0 & 89.1 \\
\hline${ }^{3} 4$ & -35.2 & -34.8 & -39.5 & -31.4 \\
\hline \multicolumn{5}{|c|}{ Singlet PES } \\
\hline${ }^{1} \mathbf{2 a}$ & 83.2 & & 111.7 & \\
\hline${ }^{1} \mathbf{e}^{b}$ & 0.0 & & 0.0 & \\
\hline${ }^{1} \mathbf{T S} \mathbf{1} \mathbf{j}^{c}$ & 175.0 & & 137.6 & \\
\hline${ }^{1} \mathbf{T S 1}^{d}$ & 126.9 & & 138.3 & \\
\hline${ }^{1}$ TS1h & 71.1 & & 81.9 & \\
\hline${ }^{1}$ TS1i & 69.4 & & 80.5 & \\
\hline${ }^{1} 4$ & 16.4 & & 25.5 & \\
\hline
\end{tabular}

${ }^{a}$ TS1h optimized to TS1m. ${ }^{b}$ 2b optimized to 2 e. ${ }^{c 1}$ TS1a optimized to ${ }^{1}$ TS1j. ${ }^{d}{ }^{1}$ TS1k was located instead of ${ }^{1}$ TS1 b.

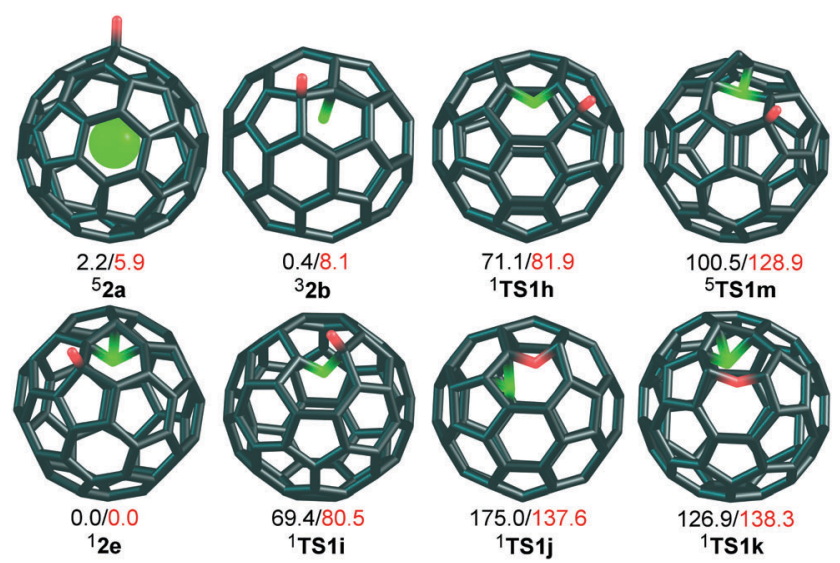

Fig. 3 Structures and relative energies in $\mathrm{kcal} \mathrm{mol}^{-1}$ at the B3LYP (black) and MP2 (red) levels for ${ }^{5} \mathbf{2} \mathbf{a},{ }^{3} \mathbf{2} \mathbf{b},{ }^{1} \mathbf{2 e}$ minima, and transition states ${ }^{1} \mathbf{T S} \mathbf{h}-\mathbf{k}$ and ${ }^{5}$ TS1m.

$39.5 \mathrm{kcal} \mathrm{mol}^{-1}$ and ${ }^{5} \mathbf{2 a} \rightarrow{ }^{5} 4$ is also exothermic by 0.1 and $16.3 \mathrm{kcal} \mathrm{mol}^{-1}$ at DFT and MP2 (Table 4), respectively.

However, hydrogenation of ${ }^{4} \mathbf{1}$ to ${ }^{1} \mathbf{2 e},{ }^{3} \mathbf{2 b}$ and ${ }^{5} \mathbf{2 a}$ is exothermic by only 44.0, 43.5 and $41.8 \mathrm{kcal} \mathrm{mol}^{-1}$ at DFT and 30.8, 22.7 and $24.9 \mathrm{kcal} \mathrm{mol}^{-1}$ at MP2, respectively. This energy gain is ca. $30-50 \mathrm{kcal} \mathrm{mol}^{-1}$ less than is necessary to overcome the barrier of nitrogen escape through the cage of $\mathrm{C}_{60}$ (for the singlet PES).
This is in contrast to the case of protonation through the cage, when initial protonation of $\mathrm{NH}_{x} @ \mathrm{C}_{60}$ leads to an energy release larger than that required to overcome the barrier to proton insertion through the $\mathrm{C}_{60}$ cage. Thus, hydrogenation by protonation is expected to be the only way for the synthesis of nitrogen hydrides inside $\mathrm{C}_{60}$.

\section{Electronic properties of $\mathrm{NH}_{4} @ \mathrm{C}_{60}$}

The formation of $\mathrm{NH}_{4} @ \mathrm{C}_{60}$ according to

$$
\mathrm{NH}_{4}^{+}+\mathrm{C}_{60}{ }^{--} \rightarrow \mathrm{NH}_{4} @ \mathrm{C}_{60}
$$

is calculated to be highly exothermic $\left(-83.9 \mathrm{kcal} \mathrm{mol}^{-1}\right.$ and $-156.5 \mathrm{kcal} \mathrm{mol}^{-1}$ at the B3LYP and MP2 levels, respectively). We performed an NPA analysis of the target species $\mathrm{NH}_{4} @ \mathrm{C}_{60}$ 13 at B3LYP both with and without an implicit representation of the solvent (benzene) to study its nature. We used a polarized continuum model (PCM) ${ }^{80-86}$ to consider solvent effects. Both calculations confirmed that the $\mathrm{NH}_{4}$ moiety carries almost a unit positive charge $(+0.97 e$ with and without PCM corrections), while the $\mathrm{C}_{60}$ moiety is correspondingly negatively charged (13). The sum of Coulson charges at the AM1 level ${ }^{87}$ leads to a similar charge of $+0.96 e$. The total charge of $\mathbf{1 3}$ is naturally zero, and the whole species 13 is a radical. Thus, $\mathrm{NH}_{4} @ \mathrm{C}_{60}$ is indeed a "concentric ion pair" more properly described as $\mathrm{NH}_{4}{ }^{+} @ \mathrm{C}_{60}{ }^{\bullet-}$, in agreement with previous theoretical studies for this and related $\mathrm{MH}_{4}{ }^{ \pm} @ \mathrm{C}_{60}{ }^{\bullet-}$ species. $^{88}$

13 has a peculiar electronic structure as its metal-free cation is confined inside the $\mathrm{C}_{60}$ anion and cannot escape from the fullerene cage, although metal containing $\mathrm{Ca}^{2+} @ \mathrm{C}_{60}{ }^{2-}$ has been observed experimentally ${ }^{89}$ and $\mathbf{M}_{3} \mathrm{~N} @ \mathrm{C}_{x}$ concentric ion pairs are known for larger fullerenes. ${ }^{90,91} 13$ is not a classical salt with two counterions held together by electrostatic forces and is also not a zwitterion, because the oppositely charged moieties are not covalently bound. Moreover, charge centers for both the positively charged ammonium ion and the fullerene $\mathrm{C}_{60}{ }^{\bullet-}$ radical anion coincide with the geometrical and mass centers of the $\mathrm{C}_{60}$ cage. The ammonium ion is thus forced to reside at the center of the $\mathrm{C}_{60}$, since otherwise the centers of positive and negative charges would be displaced, and the resulting electrostatic attraction returns $\mathrm{NH}_{4}{ }^{+}$to the $\mathrm{C}_{60}{ }^{\bullet-}$ origin. Indeed, the dipole moment of $\mathrm{NH}_{4}{ }^{+}$@ $\mathrm{C}_{60}{ }^{-}-$is essentially zero at the B3LYP level of theory. It results in an absence of charge separation and the additional stabilization of the system.

On the other hand, it is known that the naked Rydberg radical $\left[\left(\mathrm{NH}_{4}^{+}\right)\left(e^{-}\right)_{\text {Rydberg }}\right]$ readily decomposes into $\left(\mathrm{NH}_{2}{ }^{\bullet}+\mathrm{H}_{2}\right)$ and $\left(\mathrm{NH}_{3}+\mathrm{H}^{\bullet}\right),{ }^{92-100}$ which is why we have explored whether these decomposition products are more or less energetically preferable inside $\mathrm{C}_{60}$ than ion pair $\mathrm{NH}_{4}^{+} @ \mathrm{C}_{60}{ }^{--}$13. $\left(\mathrm{NH}_{2}{ }^{-}+\right.$ $\mathrm{H}_{2}$ )@ $\mathrm{C}_{60} \mathbf{1 3 a}$ is rather unstable in comparison to $\mathbf{1 3}$, since its formation from 13 is highly endothermic (by far more than $50 \mathrm{kcal} \mathrm{mol}^{-1}$ ) and thus thermodynamically unfavorable (Fig. 4). In addition, optimization of $\left(\mathrm{NH}_{3}+\mathrm{H}^{\bullet}\right) @ \mathrm{C}_{60}$ in conformation $\mathbf{1 3 b}$ at the B3LYP level, even starting from the structure with a shortened $\mathrm{C}-\mathrm{H}$ bond length $(1.08 \AA)$ terminated with the structure of $\mathrm{NH}_{4}^{+} @ \mathrm{C}_{60}{ }^{\bullet-}$ 13. $\left(\mathrm{NH}_{3}+\mathrm{H}^{\bullet}\right) @ \mathrm{C}_{60}$ (or $\mathrm{NH}_{3} @ \mathrm{C}_{60} \mathrm{H}^{\bullet}$ as hydrogen is covalently bound to the inner surface of fullerene) in 


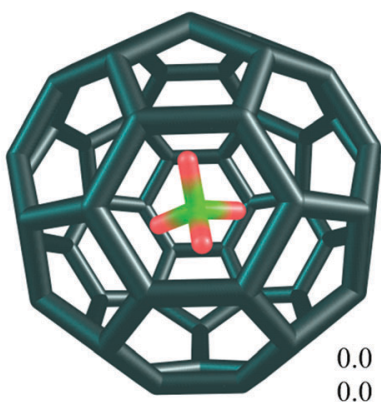

13

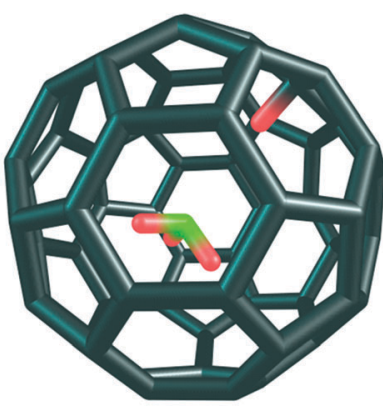

13b optimized to 13

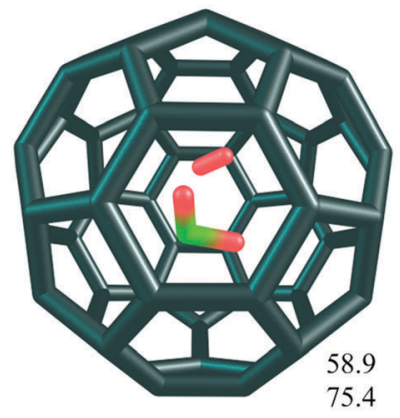

13a

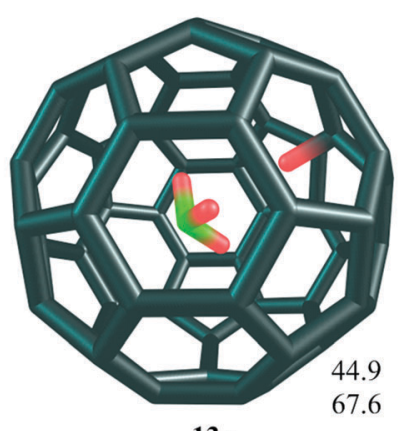

$13 \mathrm{c}$
Fig. 4 Relative energies at the B3LYP (first entry) and MP2 levels (second entry) in kcal mol ${ }^{-1}$ for $\mathrm{NH}_{4}{ }^{+} \mathrm{aC}_{60}{ }^{--}(13),\left(\mathrm{NH}_{2}{ }^{\bullet}+\mathrm{H}_{2}\right) @ \mathrm{CC}_{60}$ (13a) and two conformers of $\mathrm{NH}_{3} \mathrm{aC}_{60} \mathrm{H}^{\bullet}$ (13b and 13c).

conformation 13c is also highly endothermic and thus very unlikely to exist. Moreover, since ammonia is known to invert readily with a barrier of $5.8 \mathrm{kcal} \mathrm{mol}^{-1},{ }^{101}$ we have calculated that the barrier to ammonia inversion, which corresponds essentially to the barrier of rearrangement of $13 \mathrm{c}$ to 13 , is -0.1 and $0.7 \mathrm{kcal} \mathrm{mol}^{-1}$ at the B3LYP and MP2 levels, respectively. Thus, $\mathrm{NH}_{3} @ \mathrm{C}_{60} \mathrm{H}$ 13c obviously transforms directly into $\mathrm{NH}_{4}{ }^{+} @ \mathrm{C}_{60}{ }^{-}{ }^{-}$13. The electrostatic potential created by the ammonium cation makes the fullerene a much stronger electron acceptor than parent $\mathrm{C}_{60}$. The vertical electron affinity $\left(E A_{V}\right)$ of pure $\mathrm{C}_{60}$ calculated at the B3LYP/ $6-311+\mathrm{G}(\mathrm{d}, \mathrm{P})^{43-51,102-104}$ level on the B3LYP/6-31G(d) geometries is $2.59 \mathrm{eV}$ (close to the experimental value of $2.68 \pm 0.02 \mathrm{eV}$ ), ${ }^{105,106}$ but becomes $3.12 \mathrm{eV}$ larger when $\mathrm{NH}_{4}{ }^{+}$is placed inside the $\mathrm{C}_{60}$ (Table 5). Moreover, even the second vertical electron affinity of $\mathrm{NH}_{4}{ }^{+} @ \mathrm{C}_{60}(2.71 \mathrm{eV})$ is higher than the first $\mathrm{EA}_{\mathrm{v}}$ of neutral $\mathrm{C}_{60}$, similarly to experimental observations for $\mathrm{Ca}^{2+} @ \mathrm{C}_{60}{ }^{2-89}$ Although all further electron affinities are negative for both compounds (Table 5), no electron is transferred to $\mathrm{NH}_{4}{ }^{+}$from

Table 5 EAs of $\mathrm{NH}_{4}{ }^{+} \mathrm{aC}_{60}{ }^{n-}$ and $\mathrm{C}_{60}{ }^{n-}$ in eV at B3LYP/6-311+G(d,p) on B3LYP/6-31G(d) geometries of $\mathrm{NH}_{4}^{+} \mathrm{aC}_{60}$ and $\mathrm{C}_{60}$, respectively. The most stable spin states are taken into account

\begin{tabular}{lcr}
\hline$n$ & $\mathrm{EA}\left(\mathrm{NH}_{4}{ }^{+}\left(\mathrm{aC}_{60}{ }^{n-}\right)\right.$ & $\mathrm{EA}\left(\mathrm{C}_{60}{ }^{n-}\right)$ \\
\hline 0 & 5.71 & 2.59 \\
1 & 2.71 & -0.54 \\
2 & -0.26 & -3.16 \\
3 & -3.39 & -6.38 \\
4 & -6.25 & -9.14 \\
5 & -9.02 & -11.79
\end{tabular}

the fullerene. Note that the EAs of $\mathrm{NH}_{4}{ }^{+} @ \mathrm{C}_{60}{ }^{n-}$ plotted $v s$. those of $\mathrm{C}_{60}{ }^{n-}$ lie on a straight line $\left(R^{2}=0.9997\right)$ with a slope of 1.0 that intersects the axis at $3.1 \mathrm{eV}$ (Fig. 5). These findings are in agreement with the previous theoretical observation for $\mathrm{MH}_{4}{ }^{+} @ \mathrm{C}_{60}$ species that their EAs can be described by a simple charged sphere model and particular differences in structures of the endohedral guests has only relatively small effect of $0.1-0.6 \mathrm{eV}^{88}$

All these observations are supported by analysis of the local electron affinity $\left(\mathrm{EA}_{\mathrm{L}}\right.$, RHF-EA $\mathrm{A}_{\mathrm{L}}{ }^{107,108}$ for closed-shell and

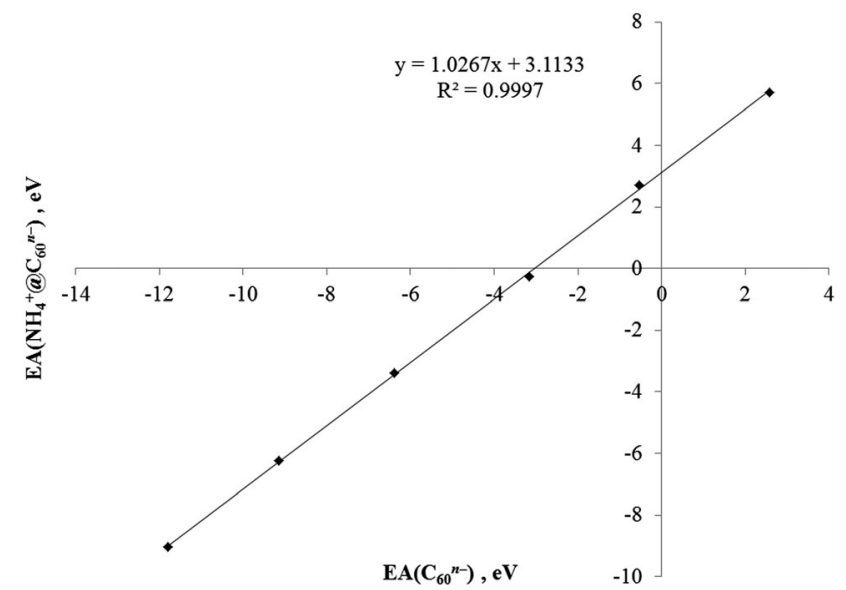

Fig. 5 Plot of $\mathrm{EA}\left(\mathrm{NH}_{4}{ }^{+}\left(\mathrm{aC}_{60}{ }^{n-}\right)\right.$ vs. $\mathrm{EA}\left(\mathrm{C}_{60}{ }^{n-}\right)$ in $\mathrm{eV}$ at the B3LYP/6$311+\mathrm{G}(\mathrm{d}, \mathrm{p})$ level on B3LYP/6-31G(d) geometries of $\mathrm{NH}_{4}{ }^{+} \mathrm{aC}_{60}$ and $\mathrm{C}_{60}$, respectively, with the linear regression line and equation.
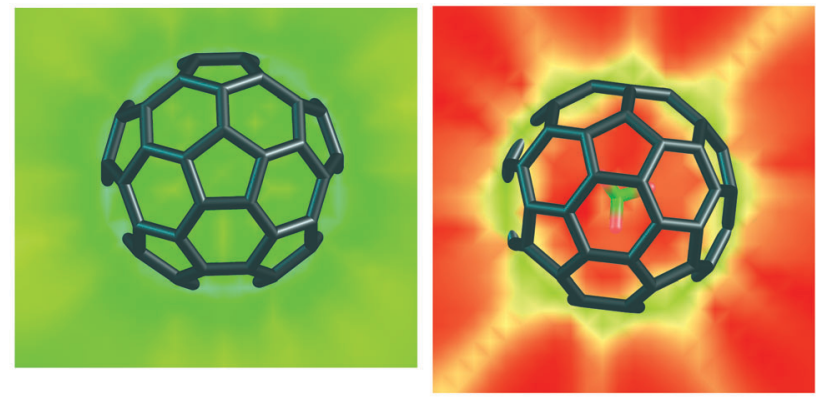

$\mathrm{C}_{60}$ $-162$

$+120$

$\mathrm{NH}_{4}^{+} @ \mathrm{C}_{60}$
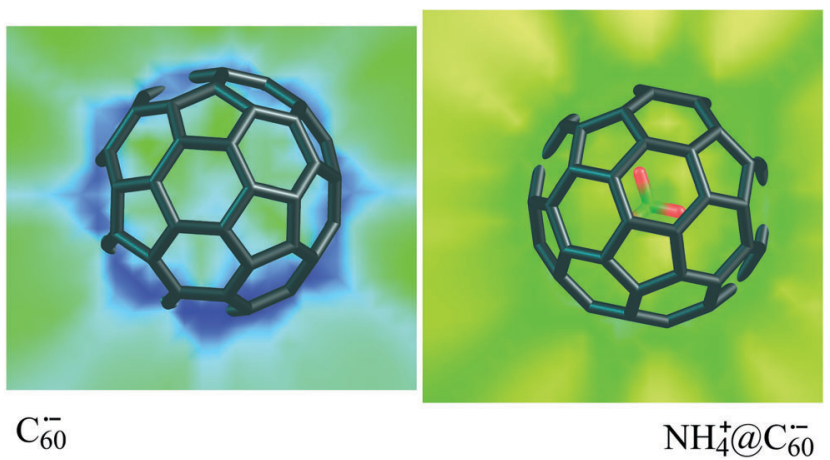

Fig. 6 Slice through the local electron affinities $\left(E A_{L}\right)$ of $\mathrm{NH}_{4}{ }^{+}\left(\mathrm{CC}_{60}\right.$ and $\mathrm{NH}_{4}{ }^{+} \mathrm{aC}_{60^{\circ}}{ }^{-}$vs. $\mathrm{C}_{60}$ and $\mathrm{C}_{60^{\circ}}{ }^{--}$at the AM1 level on B3LYP/6-31G(d) geometries. The color scale $\left(\mathrm{kcal} \mathrm{mol}^{-1}\right)$ is shown in the center. 
UHF-EA $_{\mathrm{L}}{ }^{109}$ for open-shell species) as calculated from the semiempirical wavefunction obtained using EMPIRE 2013. ${ }^{110}$ Visualized slices through the $\mathrm{EA}_{\mathrm{L}}$ for $\mathrm{C}_{60}, \mathrm{NH}_{4}^{+} @ \mathrm{C}_{60}, \mathrm{C}_{60}{ }^{\bullet-}$, and $\mathrm{NH}_{4}{ }^{+} @ \mathrm{C}_{60}{ }^{\bullet-}$ are given in Fig. 6 and show clearly that $\mathrm{NH}_{4}{ }^{+} @ \mathrm{C}_{60}$ is by far the strongest electron acceptor, in accordance with the above EAs from DFT calculations. $\mathrm{NH}_{4}{ }^{+} @ \mathrm{C}_{60}{ }^{--}$and $\mathrm{C}_{60}$ are electron acceptors with similar strength, although the former is a stronger electron acceptor. $\mathrm{C}_{60^{-}}{ }^{-}$is not an acceptor, in accordance with its negative EA.

\section{Conclusions}

We have demonstrated the possibility in principle of a new approach to the synthesis of endofullerenes via molecular "assembly" from "template" endofullerenes rather than insertion of the whole molecule into the fullerene cage or one-pot formation. $\mathrm{N} @ \mathrm{C}_{60} 1$ was chosen as the "template" for the present study, which was hydrogenated step-by-step up to ammonia inside $\mathrm{C}_{60} \mathbf{1 0}$ and the "concentric ion pair" $\mathrm{NH}_{4}^{+} @ \mathrm{C}_{60}{ }^{--} 13$ according to Scheme 1. Note that such an approach would allow us to obtain $\mathrm{NH} @ \mathrm{C}_{60}$ and $\mathrm{NH}_{2} @ \mathrm{C}_{60}$, which are open-shell systems and thus potentially interesting for spintronics. $\mathrm{NH}_{4}^{+} @ \mathrm{C}_{60}{ }^{--}$is an end product with electron affinity similar to that of $\mathrm{C}_{60}$.

The rate-determining steps of the approach are proton penetrations through the $\mathrm{C}_{60}$ cage. The most favorable pathways are proton-insertion via [5,6]-bond breaking with barriers about $90 \mathrm{kcal} \mathrm{mol}^{-1}$. The competitive pathway for the first step $\mathrm{N} @ \mathrm{C}_{60} \mathrm{H}^{+} \rightarrow \mathrm{NH}^{+} @ \mathrm{C}_{60}$ is nitrogen escape, the barriers of which are very close in energy. Meanwhile, energy gains during proton transfer to $\mathrm{NH}_{x} @ \mathrm{C}_{60}$ from $\mathrm{H}_{3}{ }^{+}$as proton carrier are about $30 \mathrm{kcal} \mathrm{mol}^{-1}$ larger than the subsequent barriers. Hydrogenation rather than protonation of nitrogen through the $\mathrm{C}_{60}$ wall leads to nitrogen escape from the fullerene cage, rather than to the formation of nitrogen hydrides at $\mathrm{C}_{60}$.

Of course, the proposed approach cannot only be used for the case of $\mathrm{N} @ \mathrm{C}_{60}$ studied here, but for other endofullerenes too. Interestingly enough, if we start from $\mathrm{CO} @ \mathrm{C}_{60}$ we can end up with methanol inside buckminsterfullerene $\mathrm{CH}_{3} \mathrm{OH} @ \mathrm{C}_{60}$ and $\mathrm{CH}_{3} \mathrm{OH}_{2}^{+}$@ $\mathrm{C}_{60}{ }^{\bullet-}$.

We note at this point that we use theory to investigate a fascinating possibility for experiments and that we make no attempt at experimental validation, which would be outside our expertise. The levels of theory are adequate that we can be confident of the general features of the calculated energy landscape and can draw conclusions about the feasibility of the approach that we suggest. We can only speculate as to possible experimental realization of the reaction sequence described here. Protonation of the intermediate endohedral species and penetration of the fullerene wall by protons should be achievable under conditions that are well established ${ }^{77-79,111}$ for ion-molecule reactions. The subsequent reduction step can be performed either by established gas-phase neutralization techniques ${ }^{11,12}$ or after isolating cation intermediates, possibly in a reducing matrix, before proceeding to the next step.

Additional experimental studies are necessary for further investigation of this interesting approach.

\section{Acknowledgements}

This work was supported by the Deutsche Forschungsgemeinschaft (DFG) as part of SFB 953 "Synthetic Carbon Allotropes" and by a grant of computer time on HRLB II at the Leibniz Rechenzentrum Munich. The authors thank Andrey A. Fokin, Tatyana E. Shubina and Walter Thiel for fruitful discussions. PD also acknowledges the financial support by the Universität Bayern e.V. via a stipend within the Bavarian Elite Aid Program. Open Access funding provided by the Max Planck Society.

\section{Notes and references}

1 H. Mauser, A. Hirsch, N. J. R. V. E. Hommes and T. Clark, J. Mol. Model., 1997, 3, 415-422.

2 T. A. Murphy, T. Pawlik, A. Weidinger, M. Höhne, R. Alcala and J.-M. Spaeth, Phys. Rev. Lett., 1996, 77, 1075-1078.

3 A. Weidinger, M. Waiblinger, B. Pietzerak and T. A. Murphy, Appl. Phys. A: Mater. Sci. Process., 1998, 66, 287-292.

4 H. Mauser, N. J. R. V. E. Hommes, T. Clark, A. Hirsch, B. Pietzak, A. Weidinger and L. Dunsch, Angew. Chem., Int. Ed. Engl., 1997, 36, 2835-2838.

5 D. S. Bethune, R. D. Johnson, J. R. Salem, M. S. D. Vries and C. S. Yannoni, Nature, 1993, 366, 123-128.

6 F. T. Edelmann, Angew. Chem., Int. Ed., 1995, 34, 981-985.

7 R. Tellgmann, N. Krawez, S.-H. Lin, I. V. Hertel and E. E. B. Campbell, Nature, 1996, 382, 407-408.

8 T. Weiske, D. K. Böhme, J. Hruscaronák, W. Krätschmer and H. Schwarz, Angew. Chem., Int. Ed. Engl., 1991, 30, 884-886.

9 T. Weiske, J. Hrusak, D. K. Böhme and H. Schwarz, Chem. Phys. Lett., 1991, 186, 459-462.

10 T. Weiske, D. K. Böhme and H. Schwarz, J. Phys. Chem., 1991, 95, 8451-8452.

11 V. T. Weiske, T. Wong, W. Krätschmer, J. K. Terlouw and H. Schwarz, Angew. Chem., 1992, 104, 242-244.

12 T. Weiske, T. Wong, W. Krätschmer, J. K. Terlouw and H. Schwarz, Angew. Chem., Int. Ed. Engl., 1992, 31, 183-185.

13 T. Weiske, H. Schwarz, A. Hirsch and T. Grösser, Chem. Phys. Lett., 1992, 199, 640-642.

14 M. Saunders, H. A. Jiménez-Vázquez, R. J. Cross and R. J. Poreda, Science, 1993, 259, 1428-1430.

15 K. Komatsu, M. Murata and Y. Murata, Science, 2005, 307, 238-240.

16 Y. Murata, M. Murata and K. Komatsu, J. Am. Chem. Soc., 2003, 125, 7152-7153.

17 T. Suetsuna, N. Dragoe, W. Harneit, A. Weidinger, H. Shimotani, S. Ito, H. Takagi and K. Kitazawa, Chem. Eur. J., 2002, 8, 5079-5083.

18 T. Peres, B. P. Cao, W. D. Cui, A. Khong, R. J. Cross, M. Saunders and C. Lifshitz, Int. J. Mass Spectrom., 2001, 210, 241-247.

19 K. Kurotobi and Y. Murata, Science, 2011, 333, 613-616.

20 M. N. Chaur, F. Melin, A. L. Ortiz and L. Echegoyen, Angew. Chem., Int. Ed., 2009, 48, 7514-7538. 
21 M. Yamada, T. Akasaka and S. Nagase, Acc. Chem. Res., 2010, 43, 92-102.

22 S. R. Plant, T. C. Ng, J. H. Warner, G. Dantelle, A. Ardavan, G. A. D. Briggs and K. Porfyrakis, Chem. Commun., 2009, 4082-4084, DOI: 10.1039/B902520k.

23 K. Sakaguchi, R. Fujii, T. Kodama, H. Nishikawa, I. Ikemoto, Y. Achiba and K. Kikuchi, Chem. Lett., 2007, 36, 832-833.

24 K. Kikuchi, K. Akiyama, K. Sakaguchi, T. Kodama, H. Nishikawa, I. Ikemoto, T. Ishigaki, Y. Achiba, K. Sueki and H. Nakahara, Chem. Phys. Lett., 2000, 319, 472-476.

25 D. Zahn and G. Seifert, J. Phys. Chem. B, 2004, 108, 16495-16498.

26 Y. Maruyama, K. Ohno, K. Esfarjani and Y. Kawazoe, Sci. Rep. Res. Inst., Tohoku Univ., Ser. A, 1996, 41, 183-186.

27 S. Patchkovskii and W. Thiel, J. Am. Chem. Soc., 1996, 118, 7164-7172.

28 S. Erkoç and L. Türker, THEOCHEM, 2003, 640, 57-61.

29 Z. Slanina, F. Uhlik, L. Adamowicz and S. Nagase, Mol. Simul., 2005, 31, 801-806.

30 M. D. Ganji, M. Mohseni and O. Goli, THEOCHEM, 2009, 913, 54-57.

31 J. Keith, E. Whitener, M. Frunzi, S.-I. Iwamatsu, S. Murata, R. J. Cross and M. Saunders, J. Am. Chem. Soc., 2008, 130, 13996-13999.

32 D. Suter and K. Lim, Phys. Rev. A: At., Mol., Opt. Phys., 2002, 65, 052309.

33 J. Twamley, Phys. Rev. A: At., Mol., Opt. Phys., 2003, 67, 052318. 34 B. Miehlich, A. Savin, H. Stoll and H. Preuss, Chem. Phys. Lett., 1989, 157, 200-206.

35 A. D. Becke, J. Chem. Phys., 1993, 98, 5648-5652.

36 P. J. Stephens, F. J. Devlin, C. F. Chabalowski and M. J. Frisch, J. Phys. Chem., 1994, 98, 11623-11627.

37 A. D. Becke, J. Chem. Phys., 1993, 98, 1372-1377.

38 A. D. Becke, Phys. Rev. A: At., Mol., Opt. Phys., 1988, 38, 3098-3100.

39 C. Lee, W. Yang and R. G. Parr, Phys. Rev. B: Condens. Matter Mater. Phys., 1988, 37, 785-789.

40 M. S. Gordon, Chem. Phys. Lett., 1980, 76, 163-168.

41 J. S. Binkley, J. A. Pople and W. J. Hehre, J. Am. Chem. Soc., 1980, 102, 939-947.

42 M. S. Gordon, J. S. Binkley, J. A. Pople, W. J. Pietro and W. J. Hehre, J. Am. Chem. Soc., 1982, 104, 2797-2803.

43 J.-P. Blaudeau, M. P. McGrath, L. A. Curtiss and L. Radom, J. Chem. Phys., 1997, 107, 5016-5021.

44 R. Ditchfield, W. J. Hehre and J. A. Pople, J. Chem. Phys., 1971, 54, 724-728.

45 M. M. Francl, W. J. Pietro, W. J. Hehre, J. S. Binkley, D. J. DeFrees, J. A. Pople and M. S. Gordon, J. Chem. Phys., 1982, 77, 3654-3665.

46 W. J. Hehre, R. Ditchfield and J. A. Pople, J. Chem. Phys., 1972, 56, 2257-2261.

47 V. A. Rassolov, J. A. Pople, M. A. Ratner and T. L. Windus, J. Chem. Phys., 1998, 109, 1223-1229.

48 R. C. Binning Jr. and L. A. Curtiss, J. Comput. Chem., 1990, 11, 1206-1216.

49 V. A. Rassolov, M. A. Ratner, J. A. Pople, P. C. Redfern and L. A. Curtiss, J. Comput. Chem., 2001, 22, 976-984.
50 P. C. Hariharan and J. A. Pople, Mol. Phys., 1974, 27, 209-214.

51 P. C. Hariharan and J. A. Pople, Theor. Chem. Acc., 1973, 28, 213-222.

52 M. J. Frisch, M. Head-Gordon and J. A. Pople, Chem. Phys. Lett., 1990, 166, 275-280.

53 M. J. Frisch, M. Head-Gordon and J. A. Pople, Chem. Phys. Lett., 1990, 166, 281-289.

54 M. Head-Gordon and T. Head-Gordon, Chem. Phys. Lett., 1994, 220, 122-128.

55 M. Head-Gordon, J. A. Pople and M. J. Frisch, Chem. Phys. Lett., 1988, 220, 503-506.

56 C. Møller and M. S. Plesset, Phys. Rev., 1934, 46, 618-622.

57 S. Sæbø and J. Almlöf, Chem. Phys. Lett., 1989, 154, 83-89.

58 G. A. Zhurko and D. A. Zhurko, ChemCraft 1.7, 2013.

59 M. J. Frisch, G. W. Trucks, H. B. Schlegel, G. E. Scuseria, M. A. Robb, J. R. Cheeseman, J. J. A. Montgomery, T. Vreven, K. N. Kudin, J. C. Burant, J. M. Millam, S. S. Iyengar, J. Tomasi, V. Barone, B. Mennucci, M. Cossi, G. Scalmani, N. Rega, G. A. Petersson, H. Nakatsuji, M. Hada, M. Ehara, K. Toyota, R. Fukuda, J. Hasegawa, M. Ishida, T. Nakajima, Y. Honda, O. Kitao, H. Nakai, M. Klene, X. Li, J. E. Knox, H. P. Hratchian, J. B. Cross, V. Bakken, C. Adamo, J. Jaramillo, R. Gomperts, R. E. Stratmann, O. Yazyev, A. J. Austin, R. Cammi, C. Pomelli, J. W. Ochterski, P. Y. Ayala, K. Morokuma, G. A. Voth, P. Salvador, J. J. Dannenberg, V. G. Zakrzewski, S. Dapprich, A. D. Daniels, M. C. Strain, O. Farkas, D. K. Malick, A. D. Rabuck, K. Raghavachari, J. B. Foresman, J. V. Ortiz, Q. Cui, A. G. Baboul, S. Clifford, J. Cioslowski, B. B. Stefanov, G. Liu, A. Liashenko, P. Piskorz, I. Komaromi, R. L. Martin, D. J. Fox, T. Keith, M. A. Al-Laham, C. Y. Peng, A. Nanayakkara, M. Challacombe, P. M. W. Gill, B. Johnson, W. Chen, M. W. Wong, C. Gonzalez and J. A. Pople, Gaussian 03, Revision D.02, Gaussian, Inc., Wallingford CT, 2004.

60 M. J. Frisch, G. W. Trucks, H. B. Schlegel, G. E. Scuseria, M. A. Robb, J. R. Cheeseman, G. Scalmani, V. Barone, B. Mennucci, G. A. Petersson, H. Nakatsuji, M. Caricato, X. Li, H. P. Hratchian, A. F. Izmaylov, J. Bloino, G. Zheng, J. L. Sonnenberg, M. Hada, M. Ehara, K. Toyota, R. Fukuda, J. Hasegawa, M. Ishida, T. Nakajima, Y. Honda, O. Kitao, H. Nakai, T. Vreven, J. J. A. Montgomery, J. E. Peralta, F. Ogliaro, M. Bearpark, J. J. Heyd, E. Brothers, K. N. Kudin, V. N. Staroverov, R. Kobayashi, J. Normand, K. Raghavachari, A. Rendell, J. C. Burant, S. S. Iyengar, J. Tomasi, M. Cossi, N. Rega, J. M. Millam, M. Klene, J. E. Knox, J. B. Cross, V. Bakken, C. Adamo, J. Jaramillo, R. Gomperts, R. E. Stratmann, O. Yazyev, A. J. Austin, R. Cammi, C. Pomelli, J. W. Ochterski, R. L. Martin, K. Morokuma, V. G. Zakrzewski, G. A. Voth, P. Salvador, J. J. Dannenberg, S. Dapprich, A. D. Daniels, O. Farkas, J. B. Foresman, J. V. Ortiz, J. Cioslowski and D. J. Fox, Gaussian 09, Revision A.02, Gaussian, Inc., Wallingford CT, 2009.

61 C. Gonzalez and H. B. Schlegel, J. Phys. Chem., 1990, 94, 5523-5527.

62 A. E. Reed, L. A. Curtiss and F. Weinhold, Chem. Rev., 1988, 88, 899-926.

63 A. E. Reed and F. Weinhold, J. Chem. Phys., 1983, 78, 4066-4073. 
64 A. E. Reed, R. B. Weinstock and F. Weinhold, J. Chem. Phys., 1985, 83, 735-746.

65 J. E. Carpenter and F. Weinhold, THEOCHEM, 1988, 46, 41-62.

66 J. P. Foster and F. Weinhold, J. Am. Chem. Soc., 1980, 102, 7211-7218.

67 F. Weinhold and J. E. Carpenter, in The Structure of Small Molecules andIons, ed. R. Naaman and Z. Vager, Plenum, 1988, pp. 227-236.

68 J. E. Carpenter, PhD thesis, University of Wisconsin, 1987. 69 Using the UFF radii as implemented in Gaussian.

70 C. Knapp, K.-P. Dinse, B. Pietzak, M. Waiblinger and A. Weidinger, Chem. Phys. Lett., 1997, 272, 433-437.

71 C. Knapp, N. Weiden and K.-P. Dinse, Magn. Reson. Chem., 2005, 43, S199-S204.

72 M. Waiblinger, K. Lips, W. Harneit, A. Weidinger, E. Dietel and A. Hirsch, Phys. Rev. B: Condens. Matter Mater. Phys., 2001, 64, 159901(E).

73 J. C. Greer, Chem. Phys. Lett., 2000, 326, 567-572.

74 J. Lu, X. Zhang and X. Zhao, Chem. Phys. Lett., 1999, 312, 85-90.

75 M. Sala, M. Hodoscek, S. Arulmozhiraja and T. Fujii, J. Phys. Chem. A, 2009, 113, 3223-3226.

76 S. W. McElvany, M. M. Ross and J. H. Callahan, Acc. Chem. Res., 1992, 25, 162-168.

77 M. D. Sefcik, J. M. S. Henis and P. P. Gaspar, J. Chem. Phys., 1974, 61, 4321-4328.

78 T. Su and M. T. Bowers, J. Am. Chem. Soc., 1973, 95, 1370-1373.

79 R. P. Clow and J. H. Futrell, J. Am. Chem. Soc., 1972, 94, 3748-3755.

80 S. Miertus, E. Scrocco and J. Tomasi, Chem. Phys., 1981, $55,117$.

81 S. Miertuš and J. Tomasi, Chem. Phys., 1982, 65, 239-245.

82 M. Cossi, V. Barone, R. Cammi and J. Tomasi, Chem. Phys. Lett., 1996, 255, 327.

83 M. T. Cances, V. Mennucci and J. Tomasi, J. Chem. Phys., 1997, 107, 3032.

84 M. Cossi, V. Barone, B. Mennucci and J. Tomasi, Chem. Phys. Lett., 1998, 286, 253.

85 V. Barone, M. Cossi and J. Tomasi, J. Comput. Chem., 1998, 19, 404.

86 V. Barone and M. Cossi, J. Phys. Chem. A, 1998, 102, 1995. 87 M. J. S. Dewar, E. G. Zoebisch, E. F. Healy and J. J. P. Stewart, J. Am. Chem. Soc., 1985, 107, 3902-3909.

88 O. P. Charkin, N. M. Klimenko, D. O. Charkin and A. M. Mebel, Russ. J. Inorg. Chem., 2004, 49, 868-880.
89 L.-S. Wang, J. M. Alford, Y. Chai, M. Diener and R. E. Smalley, Z. Phys. D: At., Mol. Clusters, 1993, 26, 297-299.

90 J. R. Pinzon, C. M. Cardona, M. A. Herranz, M. E. PlonskaBrzezinska, A. Palkar, A. J. Athans, N. Martin, A. RodriguezFortea, J. M. Poblet, G. Bottari, T. Torres, S. S. Gayathri, D. M. Guldi and L. Echegoyen, Chemistry, 2009, 15, 864-877.

91 M. N. Chaur, F. Melin, A. L. Ortiz and L. Echegoyen, Angew. Chem., Int. Ed., 2009, 48, 7514-7538.

92 H. Cardy, D. Liotard, A. Dargelos and E. Poquet, Chem. Phys., 1983, 77, 287-299.

93 F. Chen and E. R. Davidson, J. Phys. Chem. A, 2001, 105, 10915-10921.

94 E. M. Evleth and E. Kassab, Pure Appl. Chem., 1988, 60, 209-214.

95 J. Kaspar, J. Vedene, H. Smith and B. N. McMaster, Chem. Phys., 1985, 96, 81-95.

96 E. Kassab and E. M. Evleth, J. Am. Chem. Soc., 1987, 109, 1653-1661.

97 J. V. Ortiz, I. Martin, A. M. Velasco and C. Lavin, J. Chem. Phys., 2004, 120, 7949-7954.

98 J. K. Park, J. Chem. Phys., 1998, 109, 9753-9761.

99 J. K. Park, Internet Electron. J. Mol. Des., 2005, 4, 279-308.

100 A. M. Velasco, C. Lavin, I. Martin, J. Melin and J. V. Ortiz, J. Chem. Phys., 2009, 131, 024104.

101 W. Klopper, C. C. M. Samson, G. Tarczay and A. G. Csaszar, J. Comput. Chem., 2001, 22, 1306-1314.

102 T. Clark, J. Chandrasekhar, G. W. Spitznagel and P. V. R. Schleyer, J. Comput. Chem., 1983, 4, 294-301.

103 M. J. Frisch, J. A. Pople and J. S. Binkley, J. Chem. Phys., 1984, 80, 3265-3269.

104 S. Hashimoto, K. Seki, N. Sato and H. Inokuchi, J. Chem. Phys., 1982, 76, 163-172.

105 C. Brink, L. H. Andersen, P. Hvelplund, D. Mathur and J. D. Voldstad, Chem. Phys. Lett., 1995, 233, 52-56.

106 X.-B. Wang, C.-F. Ding and L.-S. Wang, J. Chem. Phys., 1998, 110, 8217-8220.

107 B. Ehresmann, B. Martin, A. H. C. Horn and T. Clark, J. Mol. Model., 2003, 9, 342-347.

108 T. Clark, J. Mol. Model., 2010, 16, 1231-1238.

109 P. O. Dral, J. Mol. Model., 2014, 20, 2134.

110 T. Clark, M. Hennemann and P. O. Dral, EMPIRE 2013, unreleased version, Universität Erlangen-Nürnberg and Cepos InSilico Ltd, 2013, see also http://www.ceposinsi lico.de/products/empire.htm, accessed May 30th, 2017.

111 J. Meyer and R. Wester, Annu. Rev. Phys. Chem., 2017, 68, 333-353. 